\title{
Educação política e pensamento freireano: sistematizando o diálogo entre luta social e saúde ${ }^{1}$
}

\author{
Political education and freirean thought: systematizing the \\ dialogue between struggle and health
}

\section{Deonardo Carnut ${ }^{2}$ \\ (D) Thais Teodoro Goraieb 3 \\ Lúcia Dias da Silva Guerra ${ }^{4}$}

\section{Resumo}

As lutas sociais na saúde são cotidianas e datam, na história recente, desde a criação do Sistema Único de Saúde (SUS) no Brasil. Neste sentido, a formação de novos coletivos que adentram a cena sócio-política e se utilizam da prática pedagógica como um instrumento de luta social vem crescendo. Essa forma de ação/militância política é o que podemos chamar, em grande medida, como 'educação política'. Assim, este relato de experiência tem como objetivo refletir sobre a experiência de amadurecimento pedagógico do coletivo 'Formação Política em Saúde', identificando os elementos fundamentais do pensamento freireano para qualificar a ação de educação política crítica para a luta social na área da saúde. Para isso realizou-se uma sistematização de experiência sobre os estudos

\footnotetext{
${ }^{1}$ Este trabalho foi desenvolvido a partir de uma primeira versão apresentada 8o. Congresso Iberoamericano de Investigação Qualitativa, 2019, Lisboa - Portugal.

2 Pós-doutor em Saúde Pública (Ciências Sociais e Humanas em Saúde) e Professor Adjunto do Centro de Desenvolvimento do Ensino Superior em Saúde (CEDESS) da Universidade Federal de São Paulo (UNIFESP). Email: leonardo.carnut@gmail.com

3 Graduanda em Medicina pela Faculdade de Ciências Médicas da Santa Casa de São Paulo (FCMSCSP). Email: thais.t.goraieb@gmail.com

${ }^{4}$ Doutora em Nutrição em Saúde Pública e Professora do Curso de Nutrição da Universidade Anhanguera, São Paulo. Email: ludsguerra@gmail.com
} 
pedagógicos do grupo de leitura 'Pedagogias Críticas e Saúde,' cujo foco foi o pensamento freiriano. 0 grupo de leitura era composto por 12 trabalhadores/estudantes da saúde, que organizavam suas seções através do método da roda. A experiência dos estudos pedagógicos críticos sobre o pensamento freiriano contribuiu para expandir a crítica sobre o processo de formação política e sua práxis, e repensar os modos de emancipação do processo educativo 'do-discente' dos membros deste coletivo.

Palavras-clave: Crítica; educação; política; formação em saúde; sistema único de saúde.

\section{Abstract}

Social struggles in health are daily and date, in recent history, since the creation of the Unified Health System (SUS) in Brazil. In this sense, the formation of new collectives that enter the socio-political scene and use the pedagogical practice as an instrument of struggle has been growing. This way of political action / activism it is what we might largely call 'political education'. It was the experience of pedagogical maturation of the group 'Political Formation in Health' in identifying the fundamentals of Freirean thought to qualify its action of critical political education. A Systematization of Experience was carried out on the reading group of 'Critical Pedagogies and Health', whose focus was the Pedagogy of Autonomy. There were 12 health workers/students who organized their sections through the Wheel Method. It was realized that the experience contributed to rethinking the modes of emancipation their 'teaching-studing'.

Keywords: Criticism; education; politics; health education; unified health system.

\section{Introdução}

A problemática da educação para a luta social e suas formas traz a tona questões importante para investigação qualitativa em educação. Estas por sua vez, possibilitam contribuir para a reflexão da luta social em saúde. É nesta ceara 
que este relato de experiência se propõe a percorrer e dialogar com o pensamento freiriano sobre educação política (Freire, 2018, 2015, 2014, 2013, 1978).

Nas universidades em todo o mundo, por mais avanços que tenham acontecido no processo de ensino-aprendizagem (formação tradicional) para 'alargar' as dimensões do trabalho em saúde (Carvalho e Ceccim, 2002), pouco se avançou concretamente na 'reconexão' da prática sanitária ao marcos do modo de produção capitalista ${ }^{5}$ (formação política). Isto tem provocando, sem dúvida, um arrefecimento gradual da orientação das disciplinas dos cursos de saúde em direção à crítica ao capitalismo e sua essência6 (Carnut et al, 2018).

Portanto, concordamos com Tragtenberg (2007) quando, em sua ácida crítica aos redutos da universidade no Brasil, ressalta o caráter classista e 'aburguesado' desta instituição, tanto do ponto de vista do corpo docente quanto dos estudantes que ali se encontram. Claro que, mesmo diante dos diversos avanços na 'popularização' da universidade pública no Brasil (Moreira et al, 2017) ainda há muito que se caminhar para abri-la à classe trabalhadora e suas frações mais populares. É neste sentido que esperar da universidade algum tipo de educação política para os trabalhadores que dali se formam seria, em última instância, uma ingenuidade pueril.

Portanto, uma pedagogia mais crítica, alinhada à emancipação da classe trabalhadora dificilmente irá advir de um contexto universitário (Mariátegui, 2010),

\footnotetext{
${ }^{5}$ Existem diversos estudos, especialmente na área da Humanização em Saúde, que desconectam a prática social da saúde do 'todo' social (entendido como o 'modo de produção'). Seja por suas opções epistemológicas ancoradas na filosofia deleuzo-guatarriana (Merhy, 2007) ou pela 'intensa intersubjetivação' do encontro assistencial tido como lócus do processo de trabalho analisado por uma episteme hermenêutico-fenomenológica (Ayres, 2007; Couto et al. 2017; Schraiber, 2008), a produção do 'social' pela saúde tem reiterado exacerbadamente a agência dos sujeitos no processo de interação. Deste movimento analítico tem derivado propostas de ações concretas que apontam politicamente para posições 'quase-liberais' sobre a prática médico-sanitária que, em certos momentos, ajustam-se ideologicamente como muita facilidade ao 'individualismo metodológico'.

${ }^{6} \mathrm{Em}$ termos práticos, veem-se os estudos de antropologia contemporânea, que, por exemplo, mapeiam o 'itinerário terapêutico' dos usuários na busca pelos serviços. Em que pese a relevante tarefa deste mapeamento, em termos 'do quê fazer?' para enfrentar o desmonte do direito à saúde, as soluções tem se restringido ao indivíduo e a sua capacidade de procura adequada pelo serviço correto. Ora, isto, em certa medida, deposita toda sorte de problemas da estrutura social no sujeito e parece ter implicações no processo educativo em saúde, pois reduz o problema, quando não bem refletido, a mera 'falta de informação'. Isto se assemelha, em última instância, à retórica 'econômica neoclássica' e seus pressupostos, dentre eles a 'assimetria de informação' como fundamento de uma suposta 'falha de mercado'. Essa assimetria na relação clínica, de fato, existe! Contudo, a questão crucial reside na pouca problematização para além desta microinteração.
} 
especialmente no âmbito da saúde. Os cursos de saúde, quando apresentam alguma inclinação ao 'social' (Abrasco, 2019), majoritariamente se restringem ao marcos do pós-modernismo (Schwartz, 2002), reafirmando os valores identitários ${ }^{7}$, familiares e comunitários $^{8}$ e refutando sistematicamente a centralidade do trabalho nas discussões que, forçosamente, levariam à crítica do modo de se produzir 'saúde' de forma totalizante.

Assim, espera-se que uma pedagogia que instigue à luta social seja o modo de trabalho de 'coletivos organizados', movimento sociais e outras formas de ação coletiva, cuja educação não-formal seja a prática de liberdade necessária para uma

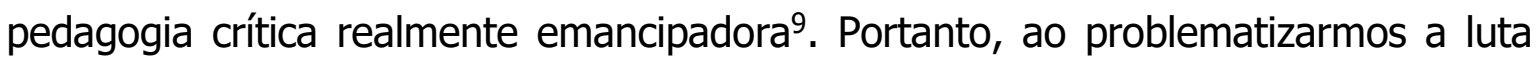

\footnotetext{
7 As assim chamadas "pautas identitárias" (gênero, sexualidade, raça, etnia, dentre outras) tem tido uma incorporação maciça nos estudos na área da Saúde, inclusive em sua interface com a Educação. Mesmo reconhecendo a importância capital da introdução destas pautas na área, esta incorporação (como era de se esperar) tem prescindido do debate de 'classe social', desconectando as 'identidades' do 'trabalho' e, por conseguinte, contribuindo para dificultar a construção da 'consciência de classe' nos trabalhadores da saúde. Atualmente, pode-se afirmar com algum grau de evidência que o ascenso neofascista vivido no Brasil é, sobretudo, uma reação à crise da 'pós-modernidade'. Segundo Cruz (2016, p. 48), "a defesa de um Estado forte e de uma sociedade hierarquizada e autoritária baseada na criação ou fortalecimento de uma 'identidade' de grupo (seja ela racial, social, étnica ou nacional)" seria uma tentativa de reordenar a sociedade para um retorno aos marcos da modernidade. Para entender a origem do debate contemporâneo sobre esta questão, ver Bensaïd (2008).

8 O apelo à retórica 'da família e das comunidades' representa, em última instância, expressões conservadoras que retiram a categoria 'trabalho' da centralidade do debate. Em saúde, como bem descrito por Guimarães (2017), a nomenclatura 'Saúde da Família' ou Medicina de 'Família e Comunidade' tem como intuito destituir a 'família e a comunidade' do conjunto de determinações da qual ela é expressão. Não à toa, esse termo foi incorporado no vocabulário do Banco Mundial sem muitas restrições. Neste sentido, mesmo que haja uma tendência do 'trabalho em saúde' em ampliarse (considerando as condições psicossociais dos usuários), ele apresenta como limite a postura 'quase psicoterapêutica' do profissional. Assim, não é de se estranhar que a perspectiva sistêmica da abordagem biopsicossocial e a perspectiva fenomenológica da abordagem centrada na pessoa tenham ganhado tanta penetrabilidade nas práticas de atenção à saúde nas unidades básicas. Se dermos um 'passo atrás' na história, este mecanismo sutil de 'desconsiderar' a relação capitaltrabalho ao olhar o 'social' no setor saúde já estava descrito em Ferrara (1993, p. 12), quando ele critica o conceito ampliado de saúde, cunhado pela OMS e consagrado na medicina social quando relata que: "Se puede expresar esto y por cierto corresponder a una visión idealista, romántica y simple de la medicina, aquella que sigue señalando por ejemplo: 'la esencia del paciente' ... la 'esencia del proceso económico-social' ... o en fin desarrollando una teoría antropológica del proceso salud-enfermedad o una simple acumulación yuxtapuesta de aspectos biológicos, sociales y psicológicos que no son el aporte certero para resolver la categoría de las ciencias de la medicina."

${ }^{9}$ As Pedagogias Críticas são um conjunto diverso de teorias pedagógicas que tem em comum a crítica ao modo de produção capitalista e ao seu sistema educacional formal. Sua gênese epistemológica pode ser remetida à crítica que Marx realizou ao programa político do Partido Sociademocrata Alemão quando estes apostam na 'subvenção estatal' para a organização da Educação Pública no livro Crítica ao Programa de Gotha (Marx, 2012). Desde então, as Pedagogias Críticas se edificaram enquanto teorias que, através de diferentes objetos, demonstram a inviabilidade de uma prática pedagógica emancipadora quando esta não parte eminentemente dos
} 
social na saúde, é essencial compreender que o marco das Pedagogias Críticas deve ser a base teórico-metodológica nestes processos de ensino-aprendizagem ${ }^{10}$.

As lutas sociais na saúde são cotidianas e datam, na história recente, desde a criação do Sistema Único de Saúde (SUS) no país (Bravo, 2011). Entre momentos de acirramento e calmarias, a militância implicada na defesa do direito à saúde sempre esteve presente durante estes 30 anos do sistema. Contudo, nos últimos 3 anos (desde o 'pré-golpe'), o engajamento de novos sujeitos e a mobilização popular para além dos partidos têm sido a marca deste período sóciohistórico em que vivemos (Jinkings et al., 2016).

Neste sentido a formação de novos coletivos pelo direito à saúde adentra a cena sócio-política e se utiliza da prática pedagógica com instrumento de luta. Essa forma de ação/militância política é o que podemos chamar, em grande medida, como 'educação política'.

A educação política, como toda categoria, é plural e encontra-se operacionalizada de diversas formas. Por ter como objetivo a 'forjar politicamente' com 'conteúdos políticos' um sujeito, pode ter como intencionalidade quaisquer vieses ideológicos, inclusive, como reportado por Marx e Engels (2007) ${ }^{11}$, aquele próprio dos interesses da burguesia.

trabalhadores em situações concretas de ação-reflexão-ação sobre a expropriação que vivem. Há diversos autores que compõem esta pedagogia, e por certo, toda e qualquer forma de classificação minimizaria sua amplitude. No entanto, para fins exclusivamente didáticos e que nos ajudaria a justificar nossa opção analítica feita neste artigo, ficamos com a classificação de Libâneo (1982) que coloca a perspectiva freireana na Abordagem Progressista.

${ }^{10}$ Mesmo assim, não nos iludamos com o processo de 'captura' em que as pedagogias críticas vêm sofrendo na sociabilidade capitalista contemporânea. Esta tende a ressignificar o conteúdo do 'crítico' e a reutilizar o termo para manutenção da ordem social vigente. Um dos caminhos em que este debate adentrou na saúde é aquele identificado nas Diretrizes Curriculares Nacionais (DCN) de todos os cursos de graduação. É sugerido como crítico o 'perfil do egresso' desejado por estes documentos. Contudo, sabe-se lá o quê cada instituição considerará como 'crítico' caso optem por seguir as DCNs! As DCNs se valem do pressuposto de que esta palavra é, por si só, autoexplicativa e não precisaria ser definida com clareza. Resultado: mesmo considerando a criticidade como um avanço na dimensão dos egressos dos cursos de saúde, na prática a crítica tem se detido à crítica sobre o melhor procedimento para o paciente, ou seja, uma crítica que o faça 'indicar' o melhor para garantir conforto ou satisfação no ato de consumir, alinhando o sentido de 'crítica' à lógica liberal. Isto aponta ao que Michael Apple nos alerta desde 2002 sobre a captura das pedagogias críticas quando institucionalizadas. Ver Apple (2002).

${ }^{11}$ Em rápida passagem de $\mathrm{O}$ Manifesto do Partido Comunista, Marx e Engels advertem que "a burguesia vive em guerra perpétua; primeiro, contra a aristocracia; depois, contra as frações da própria burguesia cujos interesses se encontram em conflito com os progressos da indústria; e sempre contra a burguesia dos países estrangeiros. Em todas essas lutas, vê-se forçada a apelar 
Em termos práxicos, podemos dividir a educação política em duas grandes perspectivas: a 'política na formação' e a 'formação política'. A 'política na formação' está relacionada com a inserção dos conteúdos sobre política (em sentido lato) nos conteúdos essenciais dos cursos de graduação, inclusive nos de saúde.

Essa aposta da educação política tem na educação formal seu lócus de ação concreta. Na atividade universitária, o espaço deste tipo de educação política cada vez tem se restringido mais às atividades de extensão universitária ou extraclasses, limitando-se a raros momentos de estudos dirigidos ou às atividades de menor "prestígio acadêmico".

Já a 'formação política' é o ato educativo de formação de quadros de liderança entre os alunos, trabalhadores e outros segmentos para organização dos assuntos de interesse de sua categoria/classe. Não raro, os membros de determinado segmento social que recebem 'formação política' assumem grêmios, diretórios acadêmicos (Moura, 2010), entidades profissionais e representações de outras ordens dentro e fora do mundo universitário alcançando posições de destaque, arregimentando a luta e, consequentemente, direcionando a decisão.

Tradicionalmente este tipo de formação detém conteúdos a respeito da conjuntura política nacional/internacional, sobre os fundamentos do capitalismo e sobre o papel da luta/assistência estudantil no mundo universitário (Cruz, 1994). Mesmo reconhecendo a relevância desta proposta, este tipo de formação corre paralela (ou à margem) aos conteúdos essenciais dos cursos de graduação. Assim, é nesse tipo de educação política em que vamos nos deter neste relato.

Compreendemos que para forjar politicamente um trabalhador ou estudante genuinamente crítico no setor saúde é essencial tomar como base pedagógica as teorias críticas. Desde 1997, vem se firmando no meio educacional em saúde a 'pedagogia libertadora' (Freire, 1996) e a 'pedagogia crítico-social dos conteúdos' defendidas por educadores de orientação marxista (Pereira, 2003). Decidimos, por uma questão de recorte analítico, focalizar nossa atenção para a que a burguesia fornece aos proletários os elementos de sua própria educação política, isto é, armas contra ela própria." [grifo nosso]. Ver Marx e Engels (2007, p. 48). 
pedagogia libertadora freireana por acreditar que esta é a mais difundida no setor saúde e ainda tem como base a participação como chave do processo pedagógico.

Diante deste cenário, é que em 2017 foi formado um coletivo chamado Formação Política em Saúde que congrega professores, estudantes e trabalhadores da área da saúde com o intuito de organizar um processo de 'trabalho de base' (Peloso, 2012) cuja orientação é a formação política crítica marxista da classe trabalhadora neste setor.

Para concretizar essa tarefa, a opção pedagógica era fundamental. Assim, escolheu-se trabalhar com as pedagogias críticas, especificamente, com métodos ativos de ensino-aprendizagem derivados do pensamento freireano. Neste sentido, um grupo de leitura em Pedagogias Críticas e Saúde foi criado para refletir sobre este trabalho de base e para estranhar a lógica de produção de conhecimento no capitalismo a partir de questionamentos como: ' $O$ que Freire nos ilumina sobre $o$ processo pedagógico da formação política que estamos vivenciando?', 'Quais pontos são essenciais?', 'Como eles podem nos ajudar a melhorar nossa prática como profissionais e educadores da àrea da saúde?' e 'Como fazer para proporcionar a curiosidade e o pensamento crítico na classe trabalhadora?'

É neste sentido que este relato de experiência tem como objetivo refletir sobre a experiência de amadurecimento pedagógico do coletivo de Formação Política em Saúde, identificando os elementos fundamentais do pensamento freireano para qualificar a ação de educação política crítica para a luta social na área da saúde.

\section{Método}

\subsection{Sistematizando a experiência de amadurecimento pedagógico para formação política}

O relato de experiência a ser descrito trata-se de uma investigação qualitativa pedagógica (Bogdan e Biklen, 1994), que se propõe sistematizar a vivência de um coletivo de trabalhadores da saúde organizado para estudos pedagógicos, em um grupo de leitura 'Pedagogias Críticas e Saúde,' cujo foco foi o pensamento freiriano. 
O grupo de leitura em 'Pedagogias Críticas e Saúde' teve a participação 12 trabalhadores com ensino superior completo, professores (mestres, doutores e pósdoutores) e estudantes de graduação e pós-graduação (mestrado e doutorado) das diversas áreas da saúde (ex.: medicina, odontologia, farmácia, enfermagem) que além da sua formação e atuação cotidiana, atuam também como moderadores e facilitadores do Coletivo Formação Política em Saúde. Este coletivo de trabalhadores reunia-se uma vez ao mês durante todo o ano de 2018, no Centro de Desenvolvimento do Ensino Superior em Saúde (CEDESS) da Universidade Federal de São Paulo, para realizarem o processo de leitura e formação no intuito de instigar a reflexão e formação pedagógica necessária para este trabalho de base (Peloso, 2012).

O grupo de leitura se organizou através do método da roda apostando em seu potencial pedagógico conforme apontado por D’Ascenzi e Lima (2013). Estes autores explicitam que este método ajuda na presença de educação continuada a partir da socialização do conhecimento dos diversos segmentos.

Para organização metodológica desta experência, apoiou-se na proposta de Oscar Jara Holliday (2006) de sistematização de experiências. Essa sistematização compreende cinco momentos: 1) o ponto de partida, 2) as perguntas iniciais, 3) a recuperação do processo vivido, 4) a reflexão de fundo e 5) os pontos de chegada.

\section{Momento 1: O ponto de partida}

A metodologia de sistematização de experiências proposta por Holliday (2006), fundamentada-se na concepção metodológica dialética. Este método foi escolhido pelo fato das pesquisas qualitativas sociais e pedagógicas que visam produzir conhecimento de forma democrática e coletiva dever levar em consideração que a prática de pesquisa necessita ser 'com' os seres humanos, e não 'em' seres humanos, e por isso, a sistematização de experiência pode ser um importante método neste caminho.

A sistematização de experiências no campo da educação apresenta algumas vantagens que dialogam com a ideia de melhorar as práticas, ou seja, no sentido de mudança em geral, seja de forma individual ou coletiva. A sistematização instiga os 
sujeitos a adquirirem ao longo deste percurso o hábito reflexivo sobre suas ações, assim como gerar práticas mais conscientes a partir da leitura crítica da realidade.

Do ponto de vista coletivo, a proposta da sistematização gera intercâmbio de aprendizagens, pois com o uso dos registros, que podem ser feitos em diversas linguagens tais como anotações, imagens, vídeos, etc, tem-se as condições de organizar as informações, as percepções e as avaliações das experiências vividas de forma a trocá-las com outras pessoas ou grupos.

Além destes elementos, sistematizar experiências contribui com 0 enriquecimento, amadurecimento e análise de alguma teoria, pois os registros realizados sobre uma experiência vivenciada também são fontes empíricas sobre os fatos observados (e por múltiplos 'viventes'), que podem colaborar na validação de afirmações teóricas apresentadas ou criar argumentos que as questionem.

O que mais interessa neste artigo é a característica ímpar que este método possui em gerar incidência política sobre os sujeitos, pois a sistematização das vivências que fundamentam as pautas de lutas dos movimentos sociais, por exemplo, também podem ser fontes de informação legítimas da realidade que se deseja transformar e, por conseguinte, de suas reivindicações.

Por isso, compreende-se a potência deste método como forma de fortalecer a identidade de grupos, pois a sistematização possibilita a capacidade de gerar uma percepção apurada dos diversos aspectos que formam a composição de grupos, delineando seu perfil, sua identidade e alinhando-a taticamente à luta.

\section{Momento 2: As perguntas iniciais}

Em termos de sistematização das leituras, foi utilizado o método de Sistematização de Experiência descrito por Holliday (2006), tendo estes como destaques para anotações ou dados. O objetivo da sistematização das leituras, tendo como dados as anotações das discussões em grupo, foi organizar as práticas para que não se 'perca o foco' e ajudar a avançar no alcance do (s) interesse(s) do grupo: de conhecer o pensamento freiriano em seu nascedouro e desenvolvimento; refletir sobre este trabalho de base, para transformação da formação e atuação enquanto trabalhadores da área da saúde e estranhar a lógica 
de produção de conhecimento no capitalismo, cuja lógica encontra na educação tradicional terreno fértil para sua reprodução. Para isso, as seguintes perguntas guiaram as leituras sobre o pensamento freireano (cf. Quadro 1 autores e textos lidos, apresentado no Momento 3): ' $O$ que Freire nos ilumina sobre o processo pedagógico da formação política que estamos vivenciando?', 'Quais pontos são essenciais?','Como eles podem nos ajudar a melhorar nossa prática como profissionais e educadores da àrea da saúde?'e 'Como fazer para proporcionar a curiosidade e o pensamento crítico na classe trabalhadora?'

Neste sentido, a concepção metodológica dialética é uma maneira de conceber a realidade, de aproximar-se dela para conhecê-la e de atuar sobre ela para transformá-la (Altamira e Canarias, 2003). É, por isso, uma maneira integral de pensar e de viver: uma filosofia. Bogdan e Biklen (1994) reforçam este argumento, destacando que idealmente a educação deveria ser o resultado de uma articulação entre teoria e prática, mas constata-se hostilidade onde deveria existir cooperação.

\section{Momento 3: A recuperação do processo vivido}

O grupo de leitura em 'Pedagogias Críticas e Saúde' teve a participação 12 trabalhadores/estudantes da área da saúde que além da sua formação e atuação cotidiana, atuam também como moderadores e facilitadores do Coletivo Formação Política em Saúde. Este coletivo tornou-se uma forma de arregimentar forças para unificar a classe trabalhadora na área da saúde compreendendo a educação política como elemento primordial à tarefa de tal envergadura.

Este coletivo de trabalhadores reunia-se uma vez ao mês durante todo o ano de 2018, no Centro de Desenvolvimento do Ensino Superior em Saúde (CEDESS) da Universidade Federal de São Paulo, para realizarem o processo de leitura e formação no intuito de instigar a reflexão e formação pedagógica necessária para este trabalho de base (Peloso, 2012).

O grupo de leitura se organizou através do método da roda apostando em seu potencial pedagógico conforme apontado por D'Ascenzi e Lima (2013). Estes autores explicitam que este método ajuda na presença de educação continuada a partir da socialização do conhecimento dos diversos segmentos. 
Neste caso, as seções eram orientadas através da leitura prévia do texto e leitura coletiva de destaques do grupo a respeito daquele elemento essencial do pensamento freireano que ajuda a qualificar a prática pedagógica no coletivo de formação política em saúde.

\section{Momento 4: A reflexão de fundo}

Discutiam-se os autores selecionados que trabalham com pedagogias críticas e que serviram de base para a reflexão feita na prática pedagógica. Assim, uma primeira agenda de leituras foi cumprida na qual foram lidos os autores Paulo Freire, Marilda Behrens e Maurício Tragtenberg com os seguintes textos (Quadro 1).

\section{Quadro 1. Autores e textos lidos nas leituras sobre Pedagogias Críticas e Saúde pelo Coletivo Formação Política em Saúde. Março-Junho, 2018.}

\begin{tabular}{|c|c|c|}
\hline $\begin{array}{l}\text { Ordem dos } \\
\text { Textos }\end{array}$ & Referências Utilizadas & $\begin{array}{l}\text { Nível de Reflexão e } \\
\text { Crítica }\end{array}$ \\
\hline Texto 1 & $\begin{array}{l}\text { FREIRE, Paulo. Virtudes do educador. Verede - Centro de } \\
\text { Estudos em Educação. } 1985\end{array}$ & $\begin{array}{l}\text { Sobre o encontro } \\
\text { educador-educando }\end{array}$ \\
\hline Texto 2 & $\begin{array}{l}\text { FREIRE, Paulo. Capítulo 1: Não há docência sem discência. } \\
\text { In: . Pedagogia da autonomia - Saberes necessários à } \\
\text { prática educativa. 1996, pp. 21-45. }\end{array}$ & $\begin{array}{l}\text { Sobre o encontro } \\
\text { educador-educando }\end{array}$ \\
\hline Texto 3 & $\begin{array}{l}\text { BEHRENS, Marilda Aparecida. Paradigmas conservadores - a } \\
\text { reprodução do conhecimento. In: } \frac{\text { O paradigma }}{\text { emergente e a prática pedagógica. p. } 39-52.1999 .}\end{array}$ & $\begin{array}{l}\text { Sobre os paradigmas } \\
\text { educacionais }\end{array}$ \\
\hline Texto 4 & $\begin{array}{l}\text { BEHRENS, Marilda Aparecida. Paradigmas inovadores - a } \\
\text { produção do conhecimento. In: } \\
\text { emergente e a prática pedagógica. p. O paradigma } \\
\text { 53-91. } 1999 .\end{array}$ & $\begin{array}{l}\text { Sobre os paradigmas } \\
\text { educacionais }\end{array}$ \\
\hline Texto 5 & $\begin{array}{l}\text { TRAGTENBERG, Maurício. A delinquência acadêmica. In: } \\
\text { Sobre educação, política e sindicalismo. 3a. ed. São Paulo: } \\
\text { Editora Unesp, } 2004 .\end{array}$ & $\begin{array}{l}\text { Sobre o lugar classista da } \\
\text { universidade e a } \\
\text { necessidade da educação } \\
\text { popular }\end{array}$ \\
\hline
\end{tabular}

Para fins analíticos, optou-se neste trabalho relatar as contribuições das Virtudes do Educador (Texto 1) e do texto "Não há docência sem discência" do livro Pedagogia da Autonomia (Texto 2) de Paulo Freire, para reflexão conjunta do coletivo sobre a prática da educação política em uma perspectiva libertadora. Havia uma compreensão de que estes textos poderiam ampliar a visão dos trabalhadores de saúde para a educação emancipadora, no que tange aos 
conteúdos marxistas. Nessa perspectiva, buscou-se o enriquecimento da atuação do coletivo enquanto educadoras e educadores progressistas e críticos na saúde.

\section{Momento 5: Os pontos de chegada}

Este momento é apresentado a seguir na sessão "Relatando a experiência: um encontro práxico da 'do-discência'".

\section{Aspectos Éticos}

Por fim, cabe mencionar que em razão dessa investigação pedagógica corresponder a um relato de experiência, a partir de destaques que os participantes elencaram dos textos, não houve a necessidade do estudo tramitar por processos éticos (Resolução CNS 466/2012).

\section{Resultados e Discussão}

\subsection{Relatando a experiência: um encontro práxico da 'do-discência'}

Partimos do fato de que o encontro proporcionado pelo grupo é um potente espaço para o processo formativo participativo. Por isso, o 'estudar juntos', expande a capacidade intelectual e ajuda a relembrar momentos de ensinoaprendizagem que dialogam com conteúdo do texto. Considerando tudo isso, podemos destacar que "na investigação pedagógica o investigador é também um praticante" (Bogdan e Biklen, 1994, p. 266). Deste modo, optou-se pela representação coletiva da análise produzida pelo grupo.

Assim, em conjunto com a recuperação dos momentos vivenciados na formação política, vários fragmentos de texto foram identificados como ensinamentos que Freire aponta e que amadurecem o pensamento pedagógico sobre o processo formativo em questão. Estes fragmentos do texto, identificados por todos os membros do grupo, tornaram-se os dados empíricos que instigaram a elaboração da crítica sobre como orientar a prática pedagógica para luta social no setor saúde.

Na leitura de "Virtudes do Educador", um dos textos fundacionais do pensamento freireano, o grupo destacou que as virtudes são atitudes a se construir e não devem ser compreendidas como uma naturalização, ou seja, não 
se deve tomá-las como um 'dom'. As virtudes do educador criam-se no ato de educar reflexivo, portanto é processo social em ato coletivo e não estão restritas ao indivíduo, conforme aponta o autor:

... estas virtudes não podem ser vistas como algo com o qual algumas pessoas nascem ou um presente que uns recebem, mas como uma forma de ser, de encarar, de comportar-se, de compreender, tudo o que se cria através da prática, na busca de transformação da sociedade. Não são qualidades abstratas, que existem independentes de nós, ao contrário, que se criam conosco (e não individualmente) (Freire, 1982, p. 1).

Neste sentido são estas as virtudes de um educador comprometido com uma transformação social na tentativa de tornar a sociedade menos injusta. Estas virtudes dialogam fortemente com o propósito do curso. Este elemento do pensamento freireano dialoga fortemente com o propósito do coletivo Formação Política em Saúde, pois compreendemos que a educação é uma das formas mais importantes de socializar as pessoas e, como instituição social "se funda na luta, se mantém viva através da luta, e esta luta deve incluir amor, conciliação, liberdade e esperança" (Freire, 2014, p. 23).

Assim, o exercício das virtudes anda em consonância com o processo de educação política crítica, já que o elemento do compromisso com a mudança e com a justiça social é condição em comum nesta formação. Conforme aponta Freire (1982, p. 1) "não são virtudes de qualquer educador mas daqueles que estão comprometidos com a transformação da sociedade injusta e na criação de uma sociedade menos injusta".

Assim, o grupo entende que é fundamental para quem se dedica à formação política crítica diminuir a distância entre discurso e prática. Este é um pré-requisito fundamental na luta política, porque ao fazermos escolhas devemos ser coerentes com elas de forma a evitar contradições incompatíveis com a nossa prática. Ao escolhermos ser educadores democráticos, o discurso tem que estar afinado com esta escolha, tem que estar coerente com a prática de tal forma que, o discurso seja a prática. Se não, nos perdemos e podemos levar os outros a se perderem também (Freire, 2014). Neste ponto Freire assevera a: 
... necessidade de diminuir a distância entre o discurso e a prática. [...] No nível da luta política, digo que é preciso diminuir a distância entre o discurso do candidato e a prática do eleito, de tal maneira que em algum momento a prática seja discurso e o discurso seja prática (Freire, 1982, p. 1).

Este processo requer também a percepção do educando sobre a formação que está sendo construída. Em um intenso processo de retroalimentação só é possível dizer que a criticidade está sendo construída quando o próprio formador também é objeto da crítica. Assim, Freire nos relembra que é importante para a prática pedagógica a crítica sobre ela própria e a quem a conduz: "mas eu não posso proclamar minha opção por uma sociedade mais justa, participativa e, ao mesmo tempo, desprezar um aluno que faz crítica de mim enquanto professor" (Freire, 1982).

E é neste terreno em que um dos binômios freireanos emerge com muita intensidade e nos faz refletir sobre a formação política realizada, especialmente por se tratar de trabalhadores na área da saúde. Devido ao pouco contato com o método pedagógico participativo e com o conteúdo sobre teoria política marxista, a tensão vivenciada ao contato com o 'conteúdo-pedagogia' tende a 'calar' o trabalhador. Ao mesmo tempo, o educador precisa compreender os "motivos" dos silêncios que ali se instalam, respeitando o tempo pedagógico de cada um. Neste aspecto:

... se trata de trabalhar a tensão permanente que se cria entre a palavra do educador e o silêncio do educando, entre a palavra dos educandos e o silêncio do educador. [...] se não sei escutar os educandos e não me exponho a palavra deles, termino discursando "para" eles (Freire, 1982, p. 2).

Assim, através das 'palavras-e-silêncios' pedagógicos, 0 processo pedagógico se conforma em sentido oposto ao tradicional. Deixa de ser uma pedagogia de respostas prontas, padronizadas e fixas, para ser uma 'pedagogia da pergunta'. O que interessa agora é perceber como os trabalhadores reelaboram suas questões fundamentais em outra direção em que a formação aponta. Assim,

é preciso que o educador testemunhe aos educados o gosto pela pergunta e o respeito à pergunta. Nos seminários de educação popular, um dos 
temas introdutórios fundamentais deve ser uma reflexão sobre a pergunta. [...] quando os companheiros riem de uma pergunta, o fazem como uma forma de fugir da situação dramática de não poder perguntar, de não poder externar uma pergunta. [...] É necessário desenvolver uma pedagogia da pergunta, porque o que sempre estamos escutando é uma pedagogia da contestação, da resposta. De maneira geral, nós professores, respondemos a perguntas que os alunos não fizeram (Freire, 1982, p. 3).

Por isso que, do ponto de vista de um trabalho pedagógico emancipador, não é possível realizar a transposição imediata da mudança objetiva para subjetiva de forma gradual e controlada justamente pela forma em que se dá o processo. Neste ponto, Freire é assertivo quando destaca:

Outro equívoco que está presente nesta tensão é o de reduzir a subjetividade a um puro reflexo da objetividade. Então, esta ingenuidade assume que só deve transformar-se a objetividade para que, no dia seguinte mude a subjetividade. Não é assim, porque os processos são dialéticos, contraditórios, processuais (Freire, 1982, p. 4).

Neste ponto, talvez as 'esquerdas' tenham esquecido como o papel do 'lugar do outro' no mundo e suas condições objetivas deve ser o ponto de partida para quaisquer processos educativos e de construção de consciência de classe. Assim, Freire nos adverte mais uma vez que:

... ninguém chega lá, partindo de lá. Isto é algo que os políticos-educadores e os educadores-políticos esqueceram-se: respeitar a compreensão de mundo, da sociedade, a sabedoria popular, o senso comum que os educandos têm. Em nome da exatidão de julgamento que os educadores, às vezes, julgam possuir, declaram que os grupos populares necessitam desta sabedoria, esquecendo que desconhecemos a percepção que estes grupos têm de sua cotidianidade, a visão que têm da sociedade. [...] temos que pensar a prática para, teoricamente, poder melhorar a prática. Fazer isso demanda uma enorme seriedade, uma grande rigorosidade (e não superficialidade). Exige estudo, criação de uma disciplina séria (Freire, 1982, p. 4). 
Portanto, a imponência e o discurso eloquente parece mais destituir a crítica do que orientar o sujeito à reflexão. Por isso, os trabalhadores que advém de cursos de saúde, por se utilizarem majoritariamente de métodos pedagógicos tradicionais sentem-se em um primeiro momento 'incomodados' como o método. É normal esperarem discursos construídos e receitas bem acabadas. No entanto, ao se depararem com esta proposta pedagógica compreendem que o processo é baseado em outra pedagogia. A mediação entre os conteúdos da educação, a qualidade do processo educativo e a técnica constituem a qualidade que a educação tem ser política; o que Freire chama de "politicidade da educação" (Freire, 2014). Contudo, mesmo assim, é necessário um equilíbrio entre o ouvir-e-falar, pois no processo educativo torna-se fundamental a 'comunicação dialógica' que exige harmonia entre 'escuta', 'fala', 'silêncio' (Freire, 2014). Assim, Freire pondera:

... mas, como escutar implica em falar também, o dever que temos de escutá-los significa o direito que igualmente temos de falar-lhes. Escutálos, no fundo é falar com eles, enquanto simplesmente falar a eles seria uma forma de não ouvi-los (Freire, 1982, p. 9).

Já na leitura do capítulo (Texto 2) "Não há docência sem discência" do livro Pedagogia da Autonomia, o grupo destacou que são saberes inerentes ao ato educativo, independentes da opção política do educador:

... devo deixar claro que, embora seja meu interesse central considerar neste texto saberes que me parecem indispensáveis à prática docente de educadoras e educadores críticos, progressistas, alguns deles são igualmente necessários a educadores conservadores. São saberes demandados pela prática educativa em si mesma, qualquer que seja a opção política do educador ou educadora (Freire, 1996, p. 12).

Neste sentido, mesmo imbuído de uma perspectiva crítica e emancipadora, Freire nos aponta que a relação prática-teoria-prática é fundamental, conformando o conceito de práxis. Essa separação artificializada entre teoria e prática gera falatório e ativismo. Este ponto é muito importante na formação política da classe trabalhadora. Em que pese a importância da construção de uma 
consciência de classe, relacionada à sua inserção no modo de produção e o alargamento do pensamento em direção à crítica à ideologia dominante, é essencial que este movimento esteja alicerçado em uma prática política. Esta é a diferença concreta entre o militante, do ativista ou do discursador.

... a reflexão crítica sobre a prática se torna uma exigência da relação Teoria/Prática sem a qual a teoria pode ir virando blábláblá e a prática, ativismo. [...] É preciso, sobretudo e aí já vai um destes saberes indispensáveis, que o formando, desde o princípio mesmo de sua experiência formadora, assumindo-se como sujeito também da produção do saber, se convença definitivamente de que ensinar não é transferir conhecimento, mas criar as possibilidades para a sua produção ou a sua construção (Freire, 1996, p. 13).

Para Freire inexiste validade de ensino que não resulta em aprendizado. Não houve ensino quando o ensinado não foi capaz de fazer o aprendiz recriar. Mesmo sob forte influência do ensino tradicional, ou seja, aquele ensino bancário onde se deposita informação no educando, mesmo assim se pode dar a volta por cima, já que:

... o aprender precedeu o ensinar ou, em outras palavras, ensinar se diluía na experiência realmente fundante de aprender. Não temo dizer que inexiste validade do ensino de que não resulta um aprendizado em que o aprendiz não se tornou capaz de recriar ou de refazer o ensinado, em que o ensinado que não foi apreendido não pode realmente ser aprendido pelo aprendiz. [...] É isso que nos leva, de um lado, à crítica e à recusa ao ensino bancário, de outro, a compreender que, apesar dele, o educando a ele submetido não está fadado a fenecer, em que pese o ensino 'bancário', que deforma a necessária criatividade do educando e do educador, o educando a ele sujeitado pode, não por causa do conteúdo cujo 'conhecimento' lhe foi transferido, mas por causa do processo mesmo de aprender, dar, como se diz na linguagem popular, a volta por cima e superar o autoritarismo e o erro epistemológico do 'bancarismo' (Freire, 1996, p. 15). 
Assim Freire demonstra que o ser humano pode em ir além dos seus condicionantes,

essa é uma das significativas vantagens dos seres humanos - a de se tornado capazes de ir mais além de seus condicionantes. Isso não significa, porém que nos seja indiferente ser um educador "bancário" ou um educador "problematizador" (Freire, 1996, p. 16).

Despir-se das certezas absolutas ou da arrogância do conhecimento é fundamental para uma formação política verdadeiramente emancipadora. Houve uma forte tradição da esquerda socialista, principalmente partidária, em realizar cursos de formação política através da retórica e erudição intelectualista. Em que pese a relevância de sua existência, muitas destas formações reproduziam a ideia do intelectual memorizador. Como Freire aponta que "o intelectual memorizador, que lê horas a fio, domestica-se ao texto [...] Fala bonito de dialética, mas pensa mecanicistamente." Neste sentido, o que Freire nos ensina é não reproduzir esta forma pedagógica com nossos caramadas compreendendo que se trata de um ciclo de produção do conhecimento, ou uma práxis do-discente:

... é uma das condições necessárias a pensar certo é não estarmos demasiado certos de nossas certezas. Por isso, é que o pensar certo, ao lado sempre da pureza e necessariamente distante do puritanismo, rigorosamente ético e gerador de boniteza, que me parece conciliável a desvergonha da arrogância de que se acha cheia ou cheio de si mesmo. [...] ensinar, aprender e pesquisar lidam com esses dois momentos do ciclo gnosiológico: o em que se ensina e se aprende o conhecimento já existente e o em que se trabalha a produção do conhecimento ainda não existente. A do-discência docência-discência - e a pesquisa, indicotomizáveis, são assim práticas requeridas por esses momentos do ciclo gnosiológico (Freire, 1996, p. 19).

Neste sentido, ao compreender o mundo do outro no processo educativo, o respeito ao senso comum é fundamental, contudo, na passagem necessária entre senso comum e saber sistemático, refletido e científico, há necessidade de compreender as angústias e decepções que podem ocorrer neste caminho. Daí 
emerge o papel essencial do educador na condução de um caminho seguro que congregue o elo entre o saber popular e o saber sistemático:

... pensar certo, do ponto de vista do professor, tanto implica o respeito ao senso comum no processo de sua necessária superação quanto o respeito e o estímulo à capacidade criadora do educando. [...] por isso mesmo pensar certo coloca ao professor ou, mais amplamente, à escola, o dever de não só respeitar os saberes com que os educandos, sobretudo os das classes populares, chegam a ela - saberes socialmente construídos na prática comunitária - mas também, como há mais de trinta anos venho sugerindo, discutir com os alunos a razão de ser de alguns desses saberes em relação com o ensino dos conteúdos (Freire, 1996; p. 18).

Ao reatar esses saberes, é papel dos educadores instigar a curiosidade crítica. Fazer-Ihes indagar a realidade e questioná-las criticamente denota reflexão e rigor, tão necessários à formação política da classe trabalhadora na saúde. Freire reforça:

Por que não discutir as implicações políticas e ideológicas de um tal descaso dos dominantes pelas áreas pobres da cidade? A ética de classe embutida neste descaso? Por que, dirá um educador reacionariamente pragmático, a escola não tem nada a ver com isso. [...] ao criticizar-se, tornando-se então, permito-me repetir, curiosidade epistemológica, metodicamente "rigorizando-se" na sua aproximação ao objeto, conota-se seus achados de maior exatidão [...] uma das tarefas precípuas da prática educativa-progressista é exatamente o desenvolvimento da curiosidade crítica, insatisfeita, indócil (Freire, 1996, p. 12).

Assim, na luta política nos forja como:

Mulheres e homens, seres histórico-sociais, nos tornamos capazes de comparar, de valorar de intervir, de escolher, de decidir, de romper, por tudo isso, nos fizemos seres éticos. Só somos porque estamos sendo (Freire, 1996, p. 15).

\section{Conclusão}


Para elaborar a crítica entre pensamento freireano, luta social e saúde, a sistematização ajudou a identificar os elementos fundamentais para esse caminho que são: a preocupação genuína do educador com a transformação da sociedade na tentativa de torná-la menos injusta, diminuir cotidianamente a distância entre teoria e prática, considerar que a criticidade que está sendo construída também é sobre o próprio formador, utilizar-se do binômio 'palavras-e-silêncios' pedagógicos, evitar a transposição imediata da mudança objetiva para a subjetiva não se esquecendo do 'lugar do outro' no mundo e suas condições objetivas na hora de identificar os avanços e limites da mudança.

Ao refletirmos sobre a experiência de amadurecimento pedagógico do coletivo de 'Formação Política em Saúde', é possível dizer que o pensamento freireano contribuiu no caminho de uma emancipação enquanto do-discentes membros do coletivo, entendendo o grupo de leitura como um momento do processo de sua própria educação política.

Desta reflexão compreendemos que Freire sugere como pontos essenciais o educador comprometido com uma transformação social, a consonância entre o processo de educação política crítica e a diminuição da distância discurso-prática e, não menos importante, alicerçar o aprendizado em uma prática política. Assim, emerge o papel essencial do educador na condução de um caminho seguro que congregue o elo entre o saber popular e o saber sistemático.

Freire ilumina esta experiência para melhorar a prática de educadores deste coletivo. Em suas palavras, é necessário considerar permanentemente que o próprio formador também é objeto da crítica. Além disso, faz-se essencial a generosidade com os trabalhadores que, ao se depararem com esta proposta pedagógica, sentem-se fortemente 'incomodados' com o método em um primeiro momento. Ademais, relembra que as 'esquerdas' frequentemente esquecem 0 papel que joga o 'lugar do outro' no mundo e como as condições objetivas dos trabalhadores devem ser o ponto de partida para quaisquer processos educativos e de construção de consciência de classe.

No afã em proporcionar a curiosidade e o pensamento crítico nesta classe trabalhadora, Freire sugere que o coletivo deva se centrar na tensão que o 
processo pedagógico gera, pois sua condução tende a 'calar' o trabalhador devido à zona de conforto pedagógico em que os trabalhadores da saúde advém. Devido ao pouco contato com o método pedagógico participativo e com os conteúdos sobre teoria política marxista, o educador do coletivo precisa compreender os "motivos" dos silêncios que ali se instala. Além disso, perceber como os trabalhadores reelaboram suas questões fundamentais em outra direção é um elemento que o educador deve estar constantemente atento. Ao fim, despir-se das certezas absolutas ou da arrogância do conhecimento é fundamental, considerando que produzir esta nova forma pedagógica com nossos camaradas se trata de um ciclo de produção do conhecimento, ou uma práxis do-discente que deve ser, de fato, nosso ponto de chegada.

Assim, ao sistematizar esta experiência de leitura, reflexão pedagógica e formação em 'Pedagogias Críticas e Saúde', pode-se dizer que se identificou com mais precisão os elementos pedagógicos e maior adaptação à realidade das virtudes freireanas para o exercício desta prática formadora. Além do fortalecimento da atuação crítica e educativa dos trabalhadores da saúde que compunham o coletivo, especialmente no que tange ao encontro educador-educando.

\section{Referências bibliográficas}

Abrasco (2019). Associação Brasileira de Saúde Coletiva. Disponível em https://bit.ly/36uTqs2

Apple, M. (2002). Pode as pedagogias críticas sustar as políticas de direita? Cadernos de Pesquisa, (116), 107-142.

Altamira, F. e Canarias, E. (2003). La sistematización de experiencias en el Sur y en el Norte: ¿iguales o diferentes? el proceso del grupo de trabajo de voluntariado de la CONGDE. Bilbao: INCYDE. Disponível em https://bit.ly/38HPXbm

Ayres, J.R. (2007). Uma concepção hermenêutica de saúde. Physis (UERJ. Impresso), (17), 43-62. 
Bensaïd, D. (2008). Os irredutíveis: teoremas da resistência para o tempo presente. São Paulo: Boitempo.

Bravo, M.I.S. (2011). Serviço Social e Reforma Sanitária: lutas sociais e práticas profissionais. São Paulo: Cortez.

Bogdan, R. e Biklen, S. (1994). Investigação qualitativa em educação: uma introdução à teoria e aos métodos. Portugal: Porto.

Carnut, L., Pereira Frazão, M., Gomes de Moura, J. e Alves de Sá Silva, A.L. (2017). Principais desafios do acolhimento na prática da atenção à saúde bucal: subsídios iniciais para uma crítica. Revista da ABENO, 17(4), 46-62.

Carvalho, Y.M. e Ceccim, R.B. (2006). Formação e educação em saúde: aprendizados com a saúde coletiva. En G.W.S. Campos, M.C.S. Minayo, M. Akerman, M. Drummond Júnior e Y.M. Carvalho (Coords.), Tratado de Saúde Coletiva (pp. 137-170). São Paulo: Editora Hucitec, Rio de Janeiro: Fiocruz.

Couto, M.T., Grangeiro, A., Venturi, G. e Levy R.B. (2017). Rendering visible heterosexually active men in Brazil: A national study on sexual behaviour, masculinities and HIV risk. Current Sociology, DOI: 10.1177/0011392117735360

Cruz, N.R. (2016). A modernidade e a pós-modernidade como gênese do fascismo: o caso dos velhos e novos integralistas brasileiros. Outros Tempos, $13(22), 26-48$.

Cruz, S.V. (1994). 1968: Movimento estudantil e crise na política brasileira. Revista de Sociologia e Política, (2), 37-55.

D'Ascenzi, L. e Lima, L.L. (2013). Análise da implementação do método da roda no sistema de saúde de campinas, SP. Sociais e Humanas, 26(01), 67-78.

Ferrara, F.A. (1993). Teoría política y salud - tomo segundo: abordando la salud. Buenos Aires: Catálogos.

Freire, P. (1978). Pedagogia do Oprimido. São Paulo: Paz e Terra.

Freire, P. (1985). Virtudes do educador. Verede: Centro de Estudos em Educação. Freire, P. (1996). Não há docência sem discência. Em P. Freire (Coord.), Pedagogia da autonomia: saberes necessários à prática educativa (pp. 21-45). São Paulo: Paz e Terra.

Freire, P. (2014). Pedagogia da solidariedade. São Paulo: Paz e Terra, 2014. 
Freire, P. (2015). Política e Educação. São Paulo: Paz e Terra.

Freire, P. (2018). Pedagogia do Compromisso: América-Latina e Educação Popular.

São Paulo: Paz e Terra.

Guimarães, E.M.S. (2017). Expressões conservadoras no trabalho em saúde: a abordagem familiar e comunitária em questão. Serviço Social e Sociedade, (130), 564-582.

Holliday, O.J. (2006). Para sistematizar experiências. Brasília: Ministério do Meio Ambiente. Disponível em https://bit.ly/36]Ax4]

Jinkings, I., Doria, K. e Cleto, M. (2016). Por que gritamos Golpe? Para entender o impeachment e a crise política no Brasil. São Paulo: Boitempo.

Libâneo, J.C. (1982). Tendências pedagógicas na prática escolar. Revista da Ande, (6), 1-35.

Mariátegui, J.C. (2010). Sobre a Educação. Em J.C. Mariátegui (Coord.), Sete ensaios de interpretação da realidade peruana (pp. 86-123). Caracas: Fundación Biblioteca Ayacucho.

Marx, K. (2012). Crítica ao programa de Gotha. São Paulo: Boitempo.

Marx, K. e Engels, F. (2007). O manifesto comunista. São Paulo: Boitempo.

Merhy, E.E. (2007). A cartografia do trabalho vivo. São Paulo: Hucitec.

Moreira, G.O., Ferraresi, F.H., Carvalho, E.M. e Amaral, E. (2017). Inclusão social e ações afirmativas no ensino superior no Brasil: para quê? Ensino Superior. Disponível em https://bit.ly/2S1Y10D

Moura, M.R.L. (2010). O Grêmio Estudantil na gestão da escola democrática: protagonismo e resiliência ou despolitização das práticas formativas? Revista de Ciências da Educação UNISAL, (23), 273-292.

Peloso, R. (2012). Trabalho de base: seleção de roteiros selecionados pelo Cepis. São Paulo: Expressão Popular.

Pereira, A.L.F. (2003). As tendências pedagógicas e a prática educativa nas ciências da saúde. Caderno de Saúde Pública, 19 (5), 1527-1534.

Schraiber, L.B. (2008). O médico e suas interações: a crise dos vínculos de confiança. São Paulo: Hucitec. 
Schwartz, G.A.D. (2002). A saúde na pós-modernidade. Revista de Direito Sanitário, 3(1), 29-37.

Tragtenberg, M. (2004). Sobre educação, política e sindicalismo. São Paulo: Editora Unesp.

Recebido em: 24 de setembro de 2019

Aceito em: 17 de dezembro de 2019 